\title{
BMJ Open Relationship between patient safety culture and patient experience in hospital settings: a scoping review protocol
}

\author{
Adel Alabdaly (D) , ${ }^{1,2}$ Deborah Debono (D) , ${ }^{3}$ Reece Hinchcliff (D),${ }^{3,4}$ Su-yin Hor (iD ${ }^{3}$
}

To cite: Alabdaly A, Debono D, Hinchcliff R, et al. Relationship between patient safety culture and patient experience in hospital settings: a scoping review protocol. BMJ Open 2021;11:e049873. doi:10.1136/ bmjopen-2021-049873

- Prepublication history and additional supplemental material for this paper are available online. To view these files, please visit the journal online (http://dx.doi.org/10.1136/ bmjopen-2021-049873).

Received 03 February 2021 Accepted 18 May 2021

Check for updates

(c) Author(s) (or their employer(s)) 2021. Re-use permitted under CC BY-NC. No commercial re-use. See rights and permissions. Published by BMJ.

${ }^{1}$ Faculty of Health, University of Technology Sydney, Sydney, New South Wales, Australia ${ }^{2}$ College of Nursing, Imam Abdulrahman Bin Faisal University, Dammam, Eastern Province, Saudi Arabia

${ }^{3}$ Centre for Health Services

Management, School of Public

Health, University of Technology

Sydney, Sydney, New South

Wales, Australia

${ }^{4}$ Australian Centre for Health Services Innovation (AusHSI) and Centre for Healthcare Transformation, School of Public Health \& Social Work, Queensland University of Technology, Brisbane, Queensland, Australia

Correspondence to

Adel Alabdaly;

A.Alabdaly@outlook.com

\section{ABSTRACT}

Introduction Hospitals commonly examine patient safety culture and other quality indicators to evaluate and improve performance in relation to quality and safety. A growing body of research has separately examined relationships between patient safety culture and patient experience on clinical outcomes and other quality indicators. However, there is a knowledge gap regarding the relationship between these two important domains. This article describes the protocol for a scoping review of published literature examining the relationship between patient safety culture and patient experience in hospital settings. The scoping review will provide an overview of research into the relationship between patient safety culture and patient experience in hospital contexts, map key concepts underpinning these domains and identify research gaps for further study.

Methods and analysis The scoping review will be conducted using the five stages of Arksey and 0'Malley's framework: identify the research question; identify relevant studies; study selection; chart data; and collate, summarise and report the results. The inclusion criteria will be applied using the Population, Concept and Context Framework. Searches will be conducted in the CINAHL, Cochrane Library, ProQuest, MEDLINE, PsycINF0, Scopus and SciELO databases, without applying date range limits. Hand-searching of grey literature will also be performed to find relevant, non-indexed literature. Data will be extracted using a standardised data extraction form developed by the Joanna Briggs Institute. Both descriptive and thematic analyses will be undertaken to scope key concepts within the body of reviewed literature.

Ethics and dissemination This type of study does not require an ethics review. The results will be submitted for publication in a peer-reviewed journal and presented at conferences.

\section{INTRODUCTION}

Enhancing the quality of hospital services by improving patient safety culture is an increasing focus of practical action and research interest in health systems. ${ }^{12}$ The quality of health services can be improved through embedding a safe and reliable culture, supported by managers who understand its influence on organisational performance,
Strengths and limitations of this study

- The study will examine the relationship between patient experience and patient safety culture in accordance with recent refinements to Arksey and O'Malley's framework for scoping reviews.

- It will explore the ways in which these domains have been conceptualised and methodologically measured or described and will map theoretical links between key concepts.

- A comprehensive search strategy will be applied, involving six bibliographical databases, without limits on study design or publication date.

- Studies not in English or Arabic languages will be excluded; this could result in relevant resources not being captured.

including clinical outcomes. ${ }^{3}{ }^{4}$ However, there is limited literature investigating the interaction between patient safety culture and patient experience, unlike the extensive research on these concepts individually.

Patient safety culture has been defined as the shared beliefs, attitudes, values and norms, which influence the behaviours and attitudes of employees, with respect to patient safety. ${ }^{5}$ Weaver et $a l^{6}$ assert that the terms 'safety culture' and 'safety climate' are frequently employed in an interchangeable manner despite their different meanings. For instance, patient safety culture represents a component of organisational culture ${ }^{7}$ that is related to the consonance of behavioural patterns, beliefs and values related to the safety of patients, which are common among representatives of a particular entity, ${ }^{8-11}$ and empowers decision-making. ${ }^{12}$ Safety climate, conversely, is considered as the outer layers of safety culture, ${ }^{13}$ more often measured at a defined time point. ${ }^{6}$ From this perspective, patient safety culture is the deeper/inner shared perceptions and developed over time, 
while safety climate refers to a snapshot of the shared perceptions (surface perceptions).

Patient experience has been defined as patient "perceptions of phenomena for which they are the best or only sources of information, such as personal comfort or effectiveness of discharge planning' (Hagertyet al, ${ }^{14} \mathrm{p} 1$ ). Patient experience requires patient involvement (especially patients with long-term conditions) in reporting their own experiences, including their perspectives of staff-patient communication, availability of information, their involvement in decision-making ${ }^{15}$ and their own safety. ${ }^{16}$

The concept of patient experience usually appears in studies focused on designing and enhancing health services based on patient feedback. In this context, the collection, analysis and application of patient experience data is widely considered a reliable approach for providing patient-centred health services. ${ }^{17}$ Providing patient-centred care, informed by patient experience, requires a cultural change from traditional approaches in which patients are viewed as passive recipients of care to more recent approaches that conceive of patients as partners in their care. ${ }^{18}$

In the literature, the terms 'patient satisfaction' and 'patient experience', which can mean quite different things, have sometimes been used interchangeably. ${ }^{19}$ While patient experience records, from a patient's perspective, what actually happened to the patient in a healthcare setting, patient satisfaction records whether the patient's experience met his or her expectations. Differences in patient satisfaction ratings for the same patient experience can reflect differences in individual's expectations. ${ }^{20}$

\section{AIM AND OBJECTIVES}

There has been much effort internationally to improve patient safety, but serious incidents continue to occur in hospital settings. This makes it important to consider patients' experiences of patient safety culture in hospitals and how safety has been conceptualised by healthcare workers.

The objective of this protocol is to: articulate the design of a scoping review aiming to explore and synthesise existing research literature regarding patients' experiences of patient safety culture in hospital settings; map the multiple perspectives and key concepts underpinning the research area; and identify research gaps. The results of this review will offer information for health organisations, researchers, healthcare professionals, policy and decision-makers, and patient groups.

\section{METHOD}

A scoping review is defined as an approach that 'aim[s] to map rapidly the key concepts underpinning a research area and the main sources and types of evidence available, and can be undertaken as stand-alone projects in their own right, especially where an area is complex or has not been reviewed comprehensively before' (Mays et al, $\left.{ }^{21} \mathrm{p} 194\right)$. In 2005, Arksey and O'Malley built on this definition and provided a methodological framework that researchers can apply to their topic. ${ }^{22}$ This study will follow the five stage framework of Arksey and O'Malley for a scoping review, ${ }^{22}$ which was refined by the Joanna Briggs Institute ${ }^{23}$ :

- Stage 1: identify the research question.

- Stage 2: identify relevant studies.

- Stage 3: study selection.

- Stage 4: chart data.

- Stage 5: collate, summarise and report the results.

The study will also follow the Preferred Reporting Items for Systematic Reviews and Meta-Analyses Extension for Scoping Reviews (online supplemental appendix 1). ${ }^{24}$

\section{PATIENT AND PUBLIC INVOLVEMENT}

No patient is involved in this study.

\section{Stage 1: identify the research question}

Research questions developed initially for scoping reviews are commonly refined during the process of iterative development prior to finalisation. The research question for this study is: "What is known regarding the relationship between patient safety culture and patient experience in hospital settings?"

\section{Stage 2: identify relevant studies}

Search terms and eligibility criteria

The inclusion criteria for the scoping review will follow the Population, Concept and Context (PCC) framework recommended by the Joanna Briggs Institute for this type of study. ${ }^{23}$ The PCC framework will be used instead of the more traditional Population, Intervention, Comparison and Outcome model, usually used for systematic reviews, because the research question does not focus on aggregating and determining the strength of evidence supporting a specific intervention.

\section{The inclusion and exclusion criteria based on the PCC framework}

Inclusion criteria

Population

- Healthcare providers in hospital contexts, including management, clinical and non-clinical staff.

- Patients who have received healthcare services in hospital settings, irrespective of demographic characteristics.

Concept

- Any article that focuses on patient safety culture, safety climate or organisational culture, in addition to patient experience or patient satisfaction.

Context

- Hospital setting.

Exclusion criteria

- Studies not reported in English or Arabic languages. 


\section{Search plan}

The electronic database search will be guided by the Boolean operators 'AND' and 'OR' to refine search strategies. Each search result gleaned from the included studies will be documented and stored in Endnote V.x9 (Clarivate Analytics), and then duplicates will be deleted. The following keywords will be used to construct the search strategies: ("safety culture" OR "patient safety culture" OR "safety climate" AND "patient experience" OR "patient satisfaction" OR "patient experience measure" OR "patient satisfaction measures" OR "quality indicators" OR "Quality Indicators, Health Care” AND "healthcare" OR "hospital" OR "Hospitals"). Online supplemental appendix 2 presents the developed search strategy in one of the selected databases (the Cochrane Library).

The review will use the three-step search phases proposed by the Joanna Briggs Institute. ${ }^{23}$ In the first phase, an initial search in two electronic databases (CINAHL and MEDLINE) appropriate to the research title will be conducted. The first search will be followed by screening the titles and abstracts of identified articles, and of the index terms used to describe the papers.

In the second phase, an additional search using all retrieved search and index terms will be undertaken across all included databases (CINAHL, Cochrane Library, ProQuest, MEDLINE, PsycINFO, Scopus and SciELO). Then, the titles and abstracts of articles for inclusion will be screened, followed by screening of the full text of potentially relevant studies to determine the final inclusion.

In the third phase, the reference lists of the final included studies will be screened for additional studies of relevance. Targeted searches for grey literature will be conducted via online hand-searching in the websites of relevant organisations in Australia and internationally, such the Agency for Healthcare Research and Quality, the Australian Commission for Safety and Quality in Healthcare, the Agency for Clinical Innovation, National Institutes of Health and Google Scholar.

\section{Stage 3: study selection}

The study selection stage will be conducted in two phases. The first phase involves the review of titles and abstracts. One reviewer (AA) will evaluate all titles and abstracts to determine whether each paper meets the eligibility criteria. Studies will be categorised as 'included', 'excluded' or 'not sure'.

Any references screened as included and not sure in the first phase will be considered for full-text review. Three reviewers ( $\mathrm{SH}, \mathrm{DD}$ and $\mathrm{RH}$ ) will each screen a random sample of $10 \%$ of titles and abstracts of studies screened as included, excluded or not sure against the selection criteria. If differences arise, all reviewers will consult to reach consensus.

\section{Stage 4: chart data}

A data extraction table will be developed to compile the data extracted during the scoping review. Online supplemental appendix 3 (attached as a separate file) contains an example of the extraction form that will be used in the study. One reviewer (AA) will extract the data from the included studies. The accuracy of the data extraction exercise will be verified by three reviewers ( $\mathrm{SH}$, $\mathrm{DD}$ and RH). Any discrepancies will be discussed during the group meetings until all the reviewers agree as to what data should be included or excluded.

Classification of data extraction:

- Author/s.

- Country.

- Aims/objective(s).

- Methodology/methods.

- Inclusion/exclusion criteria (eg, PCC).

- Types of intervention (if applicable).

- Measurement of outcomes (if applicable).

- Key results that relate to the review question.

\section{Stage 5: collate, summarise and report the results}

The methods that will be used during the research process will allow the investigators to synthesise existing literature that address this diverse field of research and develop a summary report that contains the following:

- A descriptive analysis will map the existing data and present the data distribution of studies in accordance with the date of publication and country of origin.

- A content analysis will present an outline of the theoretical and methodological strategies of the studies, and a thematic analysis will identify any prominent themes that emerge in relation to the research question and aims. The content of the included studies will be mapped broadly into three key categories:

A. Theoretical conceptualisations of patient safety culture and patient experience.

B. Measuring patient safety culture and patient experience.

C. Relationship between patient safety culture and patient experience.

\section{ETHICS AND DISSEMINATION}

The scoping review results will provide an overview of the relationship between patient safety culture and patient experience in the hospital context, and highlight areas where evidence is controversial or missing to identify priorities for further study. It does not require ethical approval as it will synthesise information that is already available from published research. The review results will be submitted to a peer-reviewed journal for publication and presented at relevant conferences.

Contributors $A A$ is the principal investigator. All authors ( $A A, S H, D D$ and $R H$ ) were involved in the design of the protocol and contributed to the manuscript. All authors approved the final manuscript.

Funding The first author is funded for a PhD scholarship from Imam Abdulrahman Bin Faisal University, Saudi Arabia.

Competing interests None declared.

Patient consent for publication Not required.

Provenance and peer review Not commissioned; externally peer reviewed. 
Supplemental material This content has been supplied by the author(s). It has not been vetted by BMJ Publishing Group Limited (BMJ) and may not have been peer-reviewed. Any opinions or recommendations discussed are solely those of the author(s) and are not endorsed by BMJ. BMJ disclaims all liability and responsibility arising from any reliance placed on the content. Where the content includes any translated material, BMJ does not warrant the accuracy and reliability of the translations (including but not limited to local regulations, clinical guidelines, terminology, drug names and drug dosages), and is not responsible for any error and/or omissions arising from translation and adaptation or otherwise.

Open access This is an open access article distributed in accordance with the Creative Commons Attribution Non Commercial (CC BY-NC 4.0) license, which permits others to distribute, remix, adapt, build upon this work non-commercially, and license their derivative works on different terms, provided the original work is properly cited, appropriate credit is given, any changes made indicated, and the use is non-commercial. See: http://creativecommons.org/licenses/by-nc/4.0/.

\section{ORCID iDs}

Adel Alabdaly http://orcid.org/0000-0003-0914-5225

Deborah Debono http://orcid.org/0000-0003-2095-156X

Reece Hinchcliff http://orcid.org/0000-0001-9920-4211

Su-yin Hor http://orcid.org/0000-0002-6498-9722

\section{REFERENCES}

1 Desmedt M, Bergs J, Vertriest S, et al. Systematic psychometric review of self-reported instruments to assess patient safety culture in primary care. J Adv Nurs 2018;74:539-49.

2 Tabrizchi N, Sedaghat M. The first study of patient safety culture in Iranian primary health centers. Acta Med Iran 2012;50:505-10.

3 Bell BG, Reeves D, Marsden K, et al. Safety climate in English general practices: workload pressures may compromise safety. $J$ Eval Clin Pract 2016;22:71-6.

4 Bonner AF, Castle NG, Perera S, et al. Patient safety culture: a review of the nursing home literature and recommendations for practice. Ann Longterm Care 2008;16:18-22.

5 Zohar D, Livne Y, Tenne-Gazit O, et al. Healthcare climate: a framework for measuring and improving patient safety. Crit Care Med 2007;35:1312-7.

6 Weaver SJ, Lubomksi LH, Wilson RF, et al. Promoting a culture of safety as a patient safety strategy: a systematic review. Ann Intern Med 2013;158:369-74.

7 Dodek PM, Wong H, Heyland DK, et al. The relationship between organizational culture and family satisfaction in critical care. Crit Care Med 2012;40:1506-12.
8 Bishop AC, Cregan BR. Patient safety culture: finding meaning in patient experiences. Int J Health Care Qual Assur 2015;28:595-610.

9 Kagan I, Porat N, Barnoy S. The quality and safety culture in general hospitals: patients', physicians' and nurses' evaluation of its effect on patient satisfaction. Int J Qual Health Care 2019;31:261-8.

10 Okafor $\mathrm{CH}$, Ugwu AC, Okon IE. Effects of patient safety culture on patient satisfaction with radiological services in Nigerian radiodiagnostic practice. J Patient Exp 2018;5:267-71.

11 Smith SA, Yount N, Sorra J. Exploring relationships between hospital patient safety culture and consumer reports safety scores. BMC Health Serv Res 2017;17:143.

12 Reason J. Achieving a safe culture: theory and practice. Work Stress 1998;12:293-306.

13 Casey T, Griffin MA, Flatau Harrison H, et al. Safety climate and culture: integrating psychological and systems perspectives. $J$ Occup Health Psychol 2017;22:341-53.

14 Hagerty TA, Samuels W, Norcini-Pala A, et al. Peplau's theory of interpersonal relations: an alternate factor structure for patient experience data? Nurs Sci Q 2017;30:160-7.

15 Hewitson P, Skew A, Graham C, et al. People with limiting longterm conditions report poorer experiences and more problems with hospital care. BMC Health Serv Res 2014;14:33.

16 Hor S, Godbold N, Collier A, et al. Finding the patient in patient safety. Health 2013;17:567-83.

17 Weldring T, Smith SMS. Patient-Reported outcomes (pros) and patient-reported outcome measures (PROMs). Health Serv Insights 2013;6:HSI.S11093-68.

18 Zimlichman E, Rozenblum R, Millenson ML. The road to patient experience of care measurement: lessons from the United States. Isr $J$ Health Policy Res 2013;2:35.

19 Beattie M, Lauder W, Atherton I, et al. Instruments to measure patient experience of health care quality in hospitals: a systematic review protocol. Syst Rev 2014;3:4.

20 The Agency for Healthcare Research \& Quality. What is patient experience? Available: https://www.ahrq.gov/cahps/about-cahps/ patient-experience/index.html [Accessed 18 Dec 2020].

21 Mays N, Roberts E, Popay J. Synthesising research evidence. In: Fulop N, Allen P, Clarke A, eds. Studying the organisation and delivery of health services: research methods. London, UK: Routledge, 2001: 188-220.

22 Arksey H, O'Malley L. Scoping studies: towards a methodological framework. Int J Soc Res Methodol 2005;8:19-32.

23 Joanna Briggs Institute. Joanna Briggs Institute reviewers' manual: 2015 edition. Methodology for JBI Scoping Reviews Adelaide. Available: https://nursing.Isuhsc.edu/JBI/docs/ReviewersManuals/ Scoping-.pdf [Accessed 3 Nov 2020].

24 Tricco AC, Lillie E, Zarin W, et al. PRISMA extension for scoping reviews (PRISMA-ScR): checklist and explanation. Ann Intern Med 2018;169:467-73. 